\title{
ATIVIDADES PRÁTICAS DO COTIDIANO E O ENSINO DE CIÊNCIAS NA EJA: a percepção de educandos e docentes
}

\author{
Daily practical activities and science teaching at EJA: Teacher and Students' \\ perception
}

Denise Westphal Merazzi ${ }^{1}$ Edson Roberto Oaigen ${ }^{2}$

\begin{abstract}
RESUMO
O tema principal do presente trabalho é o ensino de ciências na Educação de Jovens e Adultos. A investigação observou a percepção dos alunos da EJA (Ensino Fundamental) e de seus professores, a partir do desenvolvimento do conteúdo de ciências através de trabalhos envolvendo atividades práticas do cotidiano. Nesse contexto, a metodologia usada no processo de investigação baseou-se em uma pesquisa com abordagem quali-quantitativa, com a base na metodologia hermenêutica e a técnica de análise de conteúdo. No aspecto quantitativo, foi utilizado o ranking médio e os testes estatísticos de Wilcoxon. Analisando os dados, percebeu-se que a utilização de atividades práticas no ensino de Ciências na EJA é uma estratégia satisfatória no processo de ensino e aprendizagem e que existe a necessidade de instigar tais práticas na formação de jovens e adultos.
\end{abstract}

Palavras-chave: Educação de Jovens e Adultos; Ensino de Ciências; Atividades práticas.

\begin{abstract}
The main theme of this paper is the science teaching in Adults and Youth Education. It was investigated the students' perceptions of adult and youth education (elementary school) and their teachers, from science content's development through the works involving practical activities of everyday life. In this context, the methodology used in the research process was based on a survey of qualitative and quantitative approach, with hermeneutic content analysis' methodology and technique. In quantitative terms, we used the average ranking and statistical tests of Wilcoxon. Analyzing the
\end{abstract}

data obtained, it was observed that the use of practical activities in science teaching in adult education is a satisfactory strategy for teaching and learning process and that there is a need to instill these practices in young and adults' education.

Keywords: Adult and Youth Education; Science Teaching; Practical activities.

\section{INTRODUÇÃO}

A presente pesquisa faz parte de uma dissertação de mestrado defendida no ano de 2008. O estudo desenvolveu um conjunto de atividades práticas do cotidiano relacionadas aos conteúdos de Ciências na EJA - Ensino Fundamental -, promovendo a investigação do desenvolvimento da compreensão e da construção conceitual, na percepção de educandos e seus respectivos docentes.

A Educação de Jovens e Adultos se constitui como um sistema de ensino diferenciado, tendo em vista a variedade de peculiaridades apresentadas pelos educandos. Assim, é preciso que sejam utilizadas estratégias que facilitem o processo de ensino e aprendizagem, bem como atendam aos conhecimentos e valorizem os já existentes, que foram obtidos pela vivência deste educando.

\section{EDUCAÇÃO DE JOVENS E ADULTOS: CONTEXTOATUAL}

É possível compreender sob o olhar de Soares (2005) e Llosa (2000), que, apesar de cada história vivida pelo jovem ou adulto ser singular e com grande riqueza de peculiaridades, resultado de sua vivência e experiências obtidas ao longo de sua vida,

\footnotetext{
${ }^{1}$ Licenciado em Química, Mestre em Ensino de Ciências, Programa de Pós-graduação em Ensino de Ciências e Matemática, Laboratório de Ensino de Ciências, Universidade Luterana do Brasil, (PPGECIM/LPEC/ULBRA).Canoas, RS. deewwest@gmail.com

${ }^{2}$ Doutor em Educação, Programa de Pós-graduação em Ensino de Ciências e Matemática, Laboratório de Ensino de Ciências, Universidade Luterana do Brasil, (PPGECIM/LPEC/ULBRA). Canoas, RS. oaigen@terra.com.br
} 
existem momentos em comum onde essas histórias se encontram em um ponto de similaridade, seja pelas dificuldades encontradas ao retornar à sala de aula ou pela permanência na mesma, assim como os motivos que fizeram com que escola fosse abandonada ou nunca frequentada.

Soares (2005) discute a problemática do acesso e permanência que o jovem e adulto enfrentam para concluir seus estudos, evidenciando que em muitos casos o preço a ser pago, objetiva ou subjetivamente, torna-se bem alto, requerendo extremo esforço e muitas escolhas, majoritariamente pelo fato de ser um educando que trabalha. Zago (2000, p. 39) concorda dizendo que "[...] para permanecer na escola são feitos grandes sacrifícios, pois ser estudante não é um ofício que possa ser exercido sem ônus". E, no caso de o estudante ser um adulto, as dificuldades e sacrifícios tendem a aumentar.

A concepção ingênua ${ }^{3}$ do processo de educação de adultos deriva do que se pode chamar de uma educação regressiva, que considera o adulto como uma criança que cessou de desenvolver-se culturalmente. Por isso, procura aplicar-lhe os métodos de ensino e até utiliza as mesmas cartilhas que servem para a infância. Supõe-se, assim, que a educação consiste na retomada do crescimento mental de um ser humano que, culturalmente estacionou na fase infantil. O educando é considerado assim "um atrasado" (PINTO, 2005, p. 88).

A concepção de que o educando adulto é atrasado conduz aos mais graves erros pedagógicos, levando à aplicação de métodos impróprios ao invés de métodos de educação integradores do homem em sua comunidade. Este fato dificulta a formação do sujeito crítico, que compreende a sua realidade, mas que também têm a pretensão de modificá-la, nos quais o conhecimento da leitura e da escrita se faz pelo alargamento e aprofundamento da consciência crítica do homem frente à sua realidade.

$\mathrm{O}$ educando jovem e adulto deve ser percebido nas suas múltiplas dimensões, das quais se destacam a sua identidade que, além de ser de adulto ou jovem, também é de trabalhador e cidadão, considerando a sua diversidade sóciocultural. O trabalho desenvolvido com educandos jovens e adultos deve aproveitar essa riqueza de conhecimentos preexistentes, o que favorece a efetiva aprendizagem.

$\mathrm{O}$ ato de educar-se proporciona ao adulto a elevação de seu grau de conhecimento, isso modifica o sujeito e a posse dessa educação é uma exigência vital, pois é grande a exigência do convívio social e também o preconceito e exclusão para com os “menos educados".

O trabalho desenvolvido com educandos jovens e adultos deve estar vinculado ao seu cotidiano, valorizando os conhecimentos que o indivíduo traz consigo e todas as suas particularidades resultantes da sua vivência. Este princípio está claramente contemplado no PROEJA, admitindo-se assim que conforme, BRASIL (2007, p.39):

Utilizando os conhecimentos dos alunos, construídos em suas vivências dentro e fora da escola e em diferentes situações da sua vida, pode-se desenvolver uma prática conectada em situações singulares, visando conduzi-los, progressivamente, a situações de aprendizagem que exigirão reflexões cada vez mais complexas e diferenciadas para identificação de respostas, re-elaboração de concepções e construção de conhecimentos, numa dinâmica que favoreça o crescimento tanto do aluno quanto do professor.

O adulto é o membro da sociedade ao qual cabe a produção social, a direção da sociedade e a reprodução da espécie. O adulto é o homem na fase mais rica de sua existência. Portanto, a realidade social do adulto, a sua qualidade de trabalhador e o conjunto de conhecimentos que a sua vivência pressupõe tornam cada vez mais imperiosa a prática pedagógica na Educação de Jovens e Adultos, que tem o dever de ser tratada com seriedade e qualidade (PINTO, 2005).

É possível inferir que existe a necessidade de garantir a jovens e adultos, pouco ou não escolarizados, a oferta de oportunidades

\footnotetext{
${ }^{3}$ Entende-se por concepção ingênua, de acordo com Pinto (2005, p.59), aquela que é proveniente da consciência ingênua, sendo nociva no campo da educação, pois engendra ideias equivocadas, que se traduzem em ações e juízos que não coincidem com a essência do processo real, que não são, pois, verdadeiras. Não podem levar à completa e rápida solução dos problemas que considera, e somente se torna uma fonte de equívocos, de desperdício de recursos, de intentos frustrados.
} 
educacionais que sejam adequadas às suas expectativas e especificidades, mas que também é importante que essas oportunidades venham acompanhadas de uma política de discriminação positiva que implemente e facilite este processo para garantir a conclusão da formação escolar. Neste contexto, Haddad (1998, p. 116) afirma que "[...] não basta oferecer escola; é necessário criar as condições de frequência, utilizando uma política de discriminação positiva, sob risco de, mais uma vez, culpar os próprios alunos pelos seus fracassos".

Portanto, se essas oportunidades educacionais não existirem, constitui-se então uma grave negação de seu direito ao acesso à formação escolar, prevista inclusive em leis federais.

\section{METODOLOGIA}

O trabalho foi desenvolvido com os educandos do Ensino Fundamental da EJA, através da realização de atividades práticas semanais, nos meses de maio a dezembro de 2007, sendo estas atividades voltadas para conteúdos de Ciências, de forma contextualizada com o cotidiano do educando. Antes e depois da realização da atividade, os educandos respondiam a questões abertas, relacionadas às atividades realizadas e propostas pela professora, com a finalidade de avaliar se houve melhora no desempenho das respostas posteriores à atividade, indicando o progresso na aprendizagem do conteúdo.

As atividades realizadas proporcionaram o trabalho com os educandos de EJA de forma diferenciada. Todas as atividades foram desenvolvidas enfatizando a contextualização com o cotidiano, trabalhadas em grupos e de forma discutida.

Foram realizados três tipos de atividades diferentes: experimentos, práticas com material concreto e jogos pedagógicos. Aqui, foram avaliados quatro experimentos, uma prática com material concreto e um jogo pedagógico, totalizando seis atividades. Todos os trabalhos foram correlacionados com os conteúdos de Ciências do Ensino Fundamental.

Lista-se abaixo as atividades analisadas na presente pesquisa:

a) PILOTO ESTUDANDO O AR Esta atividade foi composta por três experimentos de fácil realização, sendo utilizados materiais simples, que proporcionaram a possibilidade de sua realização no refeitório da escola.

b) MEDINDO A TEMPERATURA DA ÁGUA Nesta atividade, realizou-se um experimento simples, na cozinha da escola, medindo-se as diferentes temperaturas da água e observando a relação da temperatura com o estado físico da água.

c) IDENTIFICANDO AS PARTES DO FRUTO Atividade de caráter lúdico, que propôs a construção de modelos artísticos, com a utilização de papel, tintas e canetas coloridas, partindo da observação de frutas e identificando suas características e partes.

d) ESTUDANDO O AR - Esta atividade foi composta por três experimentos de fácil realização, sendo utilizados materiais simples, que proporcionaram a possibilidade de sua realização no refeitório da escola. Esta atividade é semelhante à atividade piloto, porém, diferencia-se na formulação das questões pré e pós atividade propostas pela pesquisadora.

e) ESTUDANDO A CIÊNCIA QUE EXISTE NA NOSSA COZINHA - Trata-se de um "experimento" simples (preparação de um mousse de limão), realizado no refeitório da escola, que proporcionou a discussão e contextualização das substâncias e reações químicas que fazem parte do cotidiano.

f) JOGOS PEDAGÓGICOS SOBRE OS FUNGOS Atividade de caráter lúdico e relacionada ao tema "Fungos", na qual os alunos jogaram em grupos, sendo que os Jogos pedagógicos foram confeccionados manualmente em um Curso de Formação de Professores, no município de Alvorada e cedidos para a realização do trabalho

As respostas obtidas através dos ICD1 EJA foram quantificados através da categorização e atribuição de graus a estas categorias, sendo essa categorias diferentes em cada questão, mas igual no pré e pós teste. A categorização foi resultante da classificação progressiva dos elementos, a partir das respostas obtidas em questões abertas, de acordo com Richardson(1999, p.240).

Os dados foram analisados estatisticamente através do teste de Wilcoxon. 
Com o tratamento de dados realizado através deste teste, é possível verificar se existe diferença significativa entre os desempenhos das respostas de pré e pós-teste, sendo analisado individualmente cada aluno e comparado o indivíduo com ele mesmo.

Os ICD's ICD2 EJA e ICD3 Prof. EJA foram analisados qualitativamente, apenas observando em algumas questões o percentual de frequência das respostas.

Como amostra, obteve-se o total de 119 alunos da Educação de Jovens e Adultos e 05 de seus professores, entretanto, nem todos participaram de todas as atividades, em função da rotatividade de alunos durante o decorrer do ano letivo, estando em número máximo de respondentes 52 alunos e número mínimo de 25 alunos, totalizando em questões pré e pós-teste 902 respostas.

\section{ANÁLISE E DISCUSSÃO DOS DADOS}

Segue a análise e discussão de dados, dividida inicialmente por ICD, apresentando a abordagem qualitativa ou quali-quantitativa. Nesta introdução, é importante ressaltar os aspectos fundamentais que foram observados, destacando-se o desenvolvimento do processo de compreensão e construção conceitual dos conteúdos através das respostas coletadas antes e depois da realização das atividades e como indicativo de motivação, constatou-se através da observação do pesquisador, dos professores destes educandos e através de um questionário aplicado com os educandos e com seus

\section{Atividade 1: Piloto Estudando o Ar (38 alunos respondentes)}

Questão 1 - O que você sabe sobre o ar? Quais as suas características?

Tabela 01 - Comparação de desempenhos pré e pós atividade Questão 1/atividade1

\begin{tabular}{|c|c|c|c|}
\hline Categoria & Grau & Freq. Pré Teste & Freq. PósTeste \\
\hline Resposta incoerente & 0 & 1 & 0 \\
\hline Relação com o Vento: ar em movimento & 1 & 2 & 0 \\
\hline Relação do ar com a natureza & 2 & 5 & 0 \\
\hline Importância para a respiração & 3 & 15 & 1 \\
\hline $\begin{array}{c}\text { Importância do ar na existência dos seres } \\
\text { vivos }\end{array}$ & 4 & 14 & 3 \\
\hline Relação do ar com gases & 5 & 1 & 1 \\
\hline $\begin{array}{c}\text { Comprovação da existência do ar através da } \\
\text { alimentação da chama da vela }\end{array}$ & 6 & 0 & 4 \\
\hline Propriedades do ar & 7 & 0 & 29 \\
\hline
\end{tabular}

Seguem, abaixo, algumas respostas anteriores à atividade:

$O$ ar é muito importante, sem ele nós morreríamos por falta de ar. Ele existe mesmo a gente não vendo, o ar é invisível e está em todo lugar (Aluno 6.28A).

$O$ ar é muito importante para os seres vivos, o ar puro é bom para a saúde. Por isso é importante que não tenha poluição (Aluno 6.34A).

Oaré um vento que sopra (6.36A).

$O$ ar faz parte da natureza. Ele faz parte dos seres vivos (Aluno 6.21A).

Apresenta-se, em contraponto, algumas das afirmações posteriores a atividade:
O ar ocupa espaço e tem pressão. É muito importante para a respiração e para vida dos seres vivos (aluno 4.17A).

É possivel entender um pouquinho sobre o ar quando vemos que o fogo se apaga quando o ar termina... é por isso que quando abanamos ofogo ele aumenta (aluno 4.18A).

Em uma garrafa vazia, tá cheia de ar. Quando enche a garrafa de água o ar vai embora. Ele existe, sem a gente enxergar (aluno 4.19A).

O ar sai pelo canudinho quando você bota um pouco de água, porque a água ocupa o lugar do ar (aluno 2.20A). 


\section{Atividade 2: Medindo a temperatura da água (30 alunos respondentes)}

Questão 2 - A temperatura tem influência no estado físico da água?

Tabela 02: Comparação de desempenhos pré e pós atividade Questão 2 / atividade 2

\begin{tabular}{|c|c|c|c|}
\hline Categoria & Grau & Freq. Pré-Teste & Freq.Pós-Teste \\
\hline Não sei & 0 & 4 & 0 \\
\hline Não & 0 & 6 & 0 \\
\hline Sim. Não justificou & 1 & 20 & 0 \\
\hline Sim. Não melhorou a justificativa & 2 & 0 & 1 \\
\hline Sim. Melhorou a justificativa & 3 & 0 & 29 \\
\hline
\end{tabular}

A comparação das respostas também pode ser estabelecida através das afirmações dos educandos, que seguem listadas abaixo, primeiramente as anteriores à prática:

$A$ água pode ter diferentes temperaturas (aluno 2.24A).

Não sei $(2.25 A)$.

$\operatorname{Sim}(4.06 A ; 4.17 A)$.

Lista-se abaixo, algumas respostas posteriores à atividade, relevantes para a discussão:

Muda de estado físico conforme as temperaturas diferentes: água fria

(líquida: $\left.16^{\circ}\right)$, congelada $\left(0^{\circ}\right)$, fervendo (líquido + gás: $\left.100^{\circ}\right)$ (aluno 2.24A).

A água muda conforme a temperatura. Ambiente (líquida), Morna $\left(27^{\circ}\right)$, fervendo virando vapor $\left(97^{\circ}\right)$, gelo $\left(0^{\circ}\right)(2.25 \mathrm{~A})$.

Deu para conhecer as temperaturas da água, e quando a está em zero grau a água está em gelo, as $26^{\circ}$ está morna (liq.), e quente (liq.), em $100^{\circ}$ está virando vapor (entra em ebulição) (4.06A).

\section{Atividade 3: Identificando as partes do fruto (46 alunos respondentes)}

Questão 3 - O que são frutos?

Tabela 03: Comparação de desempenhos pré e pós atividade Questão 3 / atividade 3

\begin{tabular}{|c|c|c|c|}
\hline Categoria & Grau & Freq. Pré-Teste & Freq. Pós-Teste \\
\hline Resposta incoerente & 0 & 17 & 1 \\
\hline Não sei & 1 & 1 & 0 \\
\hline Exemplos de frutas & 2 & 10 & 0 \\
\hline Relação com a alimentação & 3 & 2 & 0 \\
\hline Relação com a alimentação / saúde & 4 & 16 & 6 \\
\hline Houve melhora na resposta & 5 & 0 & 39 \\
\hline
\end{tabular}

$\mathrm{Na}$ maioria das respostas apresentadas na tabela 3 , considerando primeiramente às anteriores à atividade, percebe-se a incoerência em relação à questão, associada à alimentação saudável ou ainda apresentavam exemplos de frutas como resposta, assim como podemos ver nas afirmações abaixo:

São coisas que precisamos para sobreviver (4.01A). (4.14A).

Alimentos saudáveis para a saúde

Maçã, pera, uva, banana (5.02A).

São sementes (5.01A).

Quando analisamos as respostas posteriores, podemos perceber que houve a melhora na maioria das respostas, sendo relacionadas de forma mais aproximada ao saber científico, assim como exemplificado nas afirmações abaixo listadas:

São protetores das sementes (4.14A).

Nascem através da fecundação das flores (5.01B).

As sementes dos frutos dão inicio a um ciclo em que a árvore nasce, se reproduz e morre. (5.01A).

São frutos da fecundação da flor $e$ protegem as sementes $(5.02 \mathrm{~A})$. 
Questão 4 - Quais as partes dos frutos que você conhece?

Tabela 04: Comparação de desempenhos pré e pós atividade Questão 4 / atividade3

Respostas anteriores à atividade:

\begin{tabular}{|c|c|c|c|}
\hline Categoria & Grau & Freq. Pré-Teste & Freq. Pós-Teste \\
\hline Resposta incoerente & 0 & 5 & 0 \\
\hline Não sei & 1 & 4 & 0 \\
\hline Não houve melhora na resposta & 1 & 0 & 1 \\
\hline Exemplos de frutas & 2 & 1 & 0 \\
\hline Partes do fruto & 3 & 36 & 1 \\
\hline Houve melhora na resposta & 4 & 0 & 44 \\
\hline
\end{tabular}

Casca e polpa (4.01A).

Semente (4.01B).

Por fora a casca e por dentro a semente e o bagaço (6.01A). (4.05B).

Sementes, cascas, gomos, folhas passam a identificar de modo mais complexo as partes do fruto, sendo que a maioria das respostas configura-se semelhantemente à afirmação abaixo:

Endocarpo, mesocarpo e epicarpo $(4.01 A, 4.01 B, 6.01 A, 4.05 B)$.

E, a partir da atividade, os educandos adultos

Questão 5 - Qual a função do fruto?

Tabela 05: Comparação de desempenhos pré e pós atividade Questão 5 /atividade3

Conforme exemplificado nas respostas (pré-teste) apresentadas abaixo:

\begin{tabular}{|c|c|c|c|}
\hline Categoria & Grau & Freq. Pré-Teste & Freq. Pós-Teste \\
\hline Resposta incoerente & 0 & 1 & 0 \\
\hline Não sei & 1 & 3 & 0 \\
\hline Relação com a alimentação & 2 & 1 & 0 \\
\hline Relação com a alimentação / saúde & 2 & 41 & 0 \\
\hline Houve melhora na resposta & 3 & 0 & 46 \\
\hline
\end{tabular}

Dar vitaminas para nos nutrir (4.22A).

Não sei (5.02A).

Nos alimentar (5.03B).

Alimento para o nosso corpo (5.04B).
Exemplifica-se em algumas respostas (pósteste) encontradas abaixo: 5.02A).

Proteger as sementes $(4.22 A ; 5.03 B$,

Proteção da semente, garantir a procriação da espécie (5.04B). 


\section{Atividade 4: Estudando o ar (54 alunos respondentes)}

Questão 6 - O ar existe? Se a resposta for sim, justifique. Tabela 06: Comparação de desempenhos pré e pós atividade Questão6/atividade 4

\begin{tabular}{|c|c|c|c|}
\hline Categoria & Grau & $\begin{array}{c}\text { Freq. Pré- } \\
\text { Teste }\end{array}$ & $\begin{array}{c}\text { Freq. Pós- } \\
\text { Teste }\end{array}$ \\
\hline O ar não existe & 0 & 1 & 0 \\
\hline Não sei & 0 & 1 & 0 \\
\hline Associado à temperatura & 1 & 2 & 0 \\
\hline Sim & 1 & 0 & 1 \\
\hline Podemos sentir o ar & 1 & 10 & 5 \\
\hline O ar é incolor & 1 & 3 & 0 \\
\hline Associado à temperatura & 1 & 2 & 0 \\
\hline Relação do ar com a natureza & 1 & 3 & 0 \\
\hline Relação com o Vento: ar em movimento & 2 & 11 & 7 \\
\hline Importância para a respiração & 3 & 10 & 3 \\
\hline Importância do ar na existência dos seres vivos & 4 & 11 & 8 \\
\hline Alimentação da chama da vela com o oxigênio & 5 & 0 & 8 \\
\hline Relação do ar com os gases & 6 & 0 & 3 \\
\hline Propriedades do ar & 7 & 0 & 19 \\
\hline
\end{tabular}

Alguns exemplos (pré-teste) são listados abaixo:

Sim, podemos sentir (6.30A).

O ar é invisível mas podemos sentir (5.01A).

Sim, nós sentimos ar no caminhar, correr, quando respiro, em fim faz parte de nossas vidas sem o ar não tem vida. (5.01B).

Exemplos pós-teste:
Sim, o ar está em todo lugar mas não podemos vê-lo, ele é literalmente invisivel mas podemos notá-lo nos movimentos das árvores ou de um papel voando, ou no nosso corpo. (6.30A)

Sim, o ar ocupa espaço. (5.01A)

Sim, vimos com a experiencia que o ar exerce a pressão, que podemos dizer que é a tensão superficial. (5.01B).

Questão 7 - Quais as características do ar?

Tabela 07: Comparação de desempenhos pré e pós atividade Questão 7 / atividade 4

\begin{tabular}{|c|c|c|c|}
\hline Categoria & Grau & $\begin{array}{c}\text { Freq. Pré- } \\
\text { Teste }\end{array}$ & $\begin{array}{c}\text { Freq. Pós- } \\
\text { Teste }\end{array}$ \\
\hline O ar não tem característica certa & 0 & 8 & 0 \\
\hline Associado à temperatura & 1 & 8 & 0 \\
\hline Podemos sentir o ar & 1 & 8 & 1 \\
\hline O ar é incolor & 1 & 13 & 1 \\
\hline Relação do ar com a natureza & 1 & 4 & 0 \\
\hline Relação com o Vento: ar em movimento & 2 & 4 & 0 \\
\hline Importância para a respiração & 3 & 5 & 1 \\
\hline Importância do ar na existência dos seres & & & 0 \\
\hline vivos & 4 & 4 & 1 \\
\hline Alimentação da chama da vela & 5 & 0 & 2 \\
\hline Relação do ar com os gases & 5 & 0 & 48 \\
\hline Propriedades do ar & 6 & 0 & \\
\hline
\end{tabular}


Apresenta-se, abaixo, algumas das respostas obtidas antes da atividade, que caracterizam o ar, a partir das percepções iniciais dos educandos:

O ar nós não podemos ver apenas sentir e respirar ele $(4.22 \mathrm{~A})$.

$O$ nosso oxigênio, nossa atmosfera, tudo que existe depende, precisa ocupar o ar (5.01B).

Ele não tem porque não conseguimos $\operatorname{ver}(5.02 \mathrm{~A})$.

$O$ ar não tem características pois não podemos ver o ar, só sentir (5.04A).
Abaixo, apresentam-se exemplos de respostas obtidas posteriormente à atividade, que, em sua maioria, demonstram relacionar às características do ar às suas propriedades:

Exerce pressão, ocupa espaço e ar alimenta ofogo com o oxigênio (4.22A).

O ar ocupa espaço, alimenta ofogo com oxigênio, consome o oxigênio, transformando em gás carbônico (5.01B).

$O$ ar exerce pressão, o ar ocupa espaço e alimenta ofogo $(5.02 \mathrm{~A})$.

Ocupa espaço, pressão, oxigênio (5.04A).

\section{Atividade 5: Estudando a ciência que existe na nossa cozinha (25 alunos respondentes)}

Questão 8 - Você acha que é possível fazer ciência na sua cozinha?

Tabela 08: Comparação de desempenhos pré e pós atividade Questão 8 / atividade 5

\begin{tabular}{|c|c|c|c|}
\hline Categoria & Grau & Freq. Pré-Teste & Freq. Pós Teste \\
\hline Sim - Não justificou. & 1 & 12 & 0 \\
\hline Ideia associada à preparação de alimentos & 2 & 11 & 1 \\
\hline $\begin{array}{c}\text { Crescimento de alimentos (pães, bolos, etc) } \\
\text { devido ao uso de fermento }\end{array}$ & 3 & 2 & 2 \\
\hline Ideia associada à evaporação (fervura) & 3 & 0 & 15 \\
\hline $\begin{array}{c}\text { Ideia associada à existência de substâncias } \\
\text { químicas nos alimentos }\end{array}$ & 4 & 0 & 1 \\
\hline $\begin{array}{c}\text { Reações ácido-base } \\
\text { corte da cebola }\end{array}$ & 4 & 0 & 5 \\
\hline $\begin{array}{c}\text { Ideia associada às lágrimas causadas pelo } \\
\text { corta }\end{array}$ & 4 & 0 & 1 \\
\hline
\end{tabular}

Abaixo, exemplifica-se através de algumas respostas obtidas anteriormente à atividade, que demonstram também a riqueza dos conhecimentos que o educando adulto apresenta:

Sim, porque da ciência podemos fazer coisas maravilhosas (5.03B).

Sim, podemos transformar alimentos. A alquimia da cozinha é estudada no mundo inteiro, fermentações, pães, queijos, conservantes, corantes, adoçantes, sal, aromas (5.04B).

$\operatorname{Sim}(4.23 A ; 4.18 A)$.

É possivel fazer ciência na minha cozinha, exemplo receitas (4.11B).

Analisando as respostas posteriores à atividade, é possível observar que as respostas apresentam melhor argumentação, já apresentando explicações de fenômenos físicos, como a exemplo da evaporação e a presença de reações químicas na preparação de alimentos, conforme exemplificado nas respostas abaixo:

Sim, porque alguns alimentos podem ser fervidos em panela de pressão (5.03B).

Podemos ver através da fervura a evaporação da água, através da mistura de leite efrutas $(5.04 B)$. (4.23A).

Sim, como a fervura da água na chaleira

Receitas, misturando ingredientes, panela de pressão, mistura de sabores (4.11B).

$\mathrm{Na}$ mistura de leite e suco de limão (4.18A). 
Questão 9 - É possível reconhecermos as reações químicas acontecerem no seu dia a dia? Justifique sua resposta.

Tabela 09: Comparação de desempenhos pré e pós atividade Questão 9 / atividade 5

\begin{tabular}{|c|c|c|c|}
\hline Categoria & Grau & $\begin{array}{c}\text { Freq. Pré- } \\
\text { Teste }\end{array}$ & Freq. Pós-Teste \\
\hline Sim - Não justificou. & 1 & 11 & 0 \\
\hline Ideia associada à preparação de alimentos & 2 & 7 & 1 \\
\hline Alergia & 2 & 1 & 0 \\
\hline Temperos & 2 & 3 & 0 \\
\hline Crescimento de alimentos (pães, bolos, etc) & 3 & 2 & 2 \\
\hline Reações ácido-base & 4 & 1 & 13 \\
\hline $\begin{array}{c}\text { Ideia associada às lágrimas causadas pelo } \\
\text { corte da cebola }\end{array}$ & 4 & 0 & 8 \\
\hline $\begin{array}{c}\text { Ideia associada à existência de substâncias } \\
\text { químicas nos alimentos }\end{array}$ & 4 & 0 & 1 \\
\hline
\end{tabular}

Assim como a questão 7, apresentada anteriormente, esta questão relaciona-se à uma atividade bem próxima do cotidiano do educando, principalmente se ele for adulto, então percebe-se especificidades e riqueza nas respostas apresentadas anteriormente à atividade, relacionando as reações químicas observadas no dia a dia. Observa-se isto a exemplo de algumas respostas obtidas anteriormente à atividade que, seguem-se abaixo:

Sim, com fermento de pão (4.05A).

$\operatorname{Sim}(4.01 B, 4.07 A)$.

Sim, os produtos que usamos no cabelo, a química do azeite de fritar (4.06A)
Nas respostas posteriores à atividade, percebe-se uma melhor argumentação na percepção dessas reações, conforme apresentase em algumas respostas abaixo:

Sim, porque a cebola é um exemplo disso, ela é muito ácida e irrita os olhos (4.01B).

Sim, existem muitas substancias químicas nos ingredientes (4.05A).

Sim, na mistura da coca-cola com o açúcar, aspirina, quando picamos a cebola começa a arder olho e a chorar (4.06A).

$\mathrm{Na}$ maionese, encontramos reações químicas, no pão, encontramos reações (4.07A).

\section{Atividade 6: Jogos Pedagógicos sobre os fungos (43 alunos respondentes)}

Questão 10 - O que você sabe sobre os fungos?

Tabela 10: Comparação de desempenhos pré e pós atividade Questão 10 / atividade 6

\begin{tabular}{|c|c|c|c|}
\hline Categoria & Grau & $\begin{array}{c}\text { Freq. Pré- } \\
\text { Teste }\end{array}$ & Freq. Pós-Teste \\
\hline Não sei & 0 & 4 & 0 \\
\hline Resposta incoerente & 0 & 2 & 0 \\
\hline Relação com as bactérias & 0 & 29 & 2 \\
\hline Exemplos parcialmente corretos & 1 & 4 & 0 \\
\hline Relação com doenças & 2 & 2 & 11 \\
\hline Relação com o habitat & 2 & 2 & 1 \\
\hline $\begin{array}{c}\text { Exemplos corretos e associados às } \\
\text { características }\end{array}$ & 3 & 0 & 29 \\
\hline \multicolumn{2}{|c|}{}
\end{tabular}


Nas respostas anteriores à atividade, percebe-se que existe uma confusão quanto à definição do que é um fungo, estabelecendo na grande maioria das respostas que o fungo é uma bactéria, conforme exemplificado com algumas respostas abaixo:

\section{São bactérias (4.07B).}

São bichos que se hospedam em restos de comida (4.08A).

São bactérias que ficam em alimento embolorados (4.08B).

São as bactérias que encontramos no lixo (4.11B)

Eu sei que são bactérias que causam as doenças (4.18A).

Nas respostas posteriores à atividade, percebe-se que há uma melhora significativa no desempenho das respostas, estando estas em sua maioria relacionadas às características dos fungos e citando exemplos corretos, ou ainda relacionando os fungos às doenças. Apenas algumas respostas permaneceram inalteradas, ainda resultantes de concepções errôneas ou confusas sobre o assunto. Podemos identificar a melhora, conforme algumas respostas listadas abaixo:

São organismos vivos, com muitas células, diferente das bactérias, podem fermentar e decompor as coisas, e causar doenças nos seres humanos (4.07B).

Hospedam-se principalmente em lugares úmidos, podem ser decompositores ou parasitas, doenças ou comestiveis (4.08A).

Podem ser doenças de animais e homens e mulheres, como a frieira e micose (4.08B). (4.11B)

Fungos são doenças que pegam no pé

Eles causam doenças na pele e nas unhas, são parasitas e decompositores (4.18A).

Questão 11 - Dê exemplos de fungos.

Tabela 11: Comparação de desempenhos pré e pós atividade Questão 11 / atividade 6

\begin{tabular}{|c|c|c|c|}
\hline Categoria & Grau & Freq. Pré-Teste & $\begin{array}{c}\text { Freq. Pós- } \\
\text { Teste }\end{array}$ \\
\hline Não sei & 0 & 1 & 0 \\
\hline Exemplos incorretos & 0 & 1 & 0 \\
\hline Resposta incoerente & 0 & 2 & 0 \\
\hline Exemplos parcialmente corretos & 1 & 5 & 0 \\
\hline Exemplos corretos & 2 & 34 & 43 \\
\hline
\end{tabular}

Esta questão apresenta, de forma peculiar, uma grande riqueza nos conhecimentos prévios apresentados pelos educandos, demonstrando que as dificuldades se encontram em sua maioria na formulação e compreensão de conceitos, mas que, quando se trata de oferecer exemplos, o educando adulto apresenta respostas corretas, que podem ser decorrentes da experiência de sua vivência.

Pode-se se observar este fato na tabela apresentada acima e também nas respostas exemplificadas abaixo, que aparecem de forma muito semelhante nas respostas posteriores e anteriores à atividade
Apresentam-se abaixo as quatro primeiras respostas como sendo anteriores à atividade e as próximas quatro como as respostas posteriores:

Mofo (4.11B).

Frieira, bicho de pé, unheiro (4.18A).

Frieira, chulé, bolor (4.22A).

Cogumelos (5.04B).

Cogumelo, mofos no pão, bolor na parede, frieira (4.11B).

Fermento, bicho de pé, unheiro, micose (4.18A).

Pão bolorado, pé com frieira, frutas apodrecidas $(4.11 \mathrm{~B})$.

Limo, cogumelo (5.04B). 
Questão 12 - Os fungos podem ser comestíveis?

Tabela 12: Comparação de desempenhos pré e pós atividade Questão 12 / atividade 6

\begin{tabular}{|c|c|c|c|}
\hline Categoria & Grau & $\begin{array}{c}\text { Freq. Pré- } \\
\text { Teste }\end{array}$ & $\begin{array}{c}\text { Freq. Pós- } \\
\text { Teste }\end{array}$ \\
\hline Resposta incoerente & 0 & 1 & 0 \\
\hline Não sei & 0 & 2 & 0 \\
\hline Não & 0 & 4 & 0 \\
\hline Sim & 1 & 14 & 7 \\
\hline Sim e exemplos incorretos & 1 & 6 & 0 \\
\hline Sim e exemplos corretos & 2 & 3 & 1 \\
\hline
\end{tabular}

Nesta questão, podemos observar que as respostas anteriores à atividade, em sua maioria estavam corretas, porém não apresentaram argumentações ou apresentavam exemplos incorretos ou parcialmente correto. Podemos observar este fato em algumas das respostas apresentadas abaixo:

Sim, queijo com bolor (5.03B).

$\operatorname{Sim}(5.04 B)$.

Sim, o cogumelo é um fungo, mas depende tem uns que pode comer outros não (5.05A).
Posteriormente à atividade, pode-se observar que, em sua maioria, as respostas permanecem corretas, porém, apresentam em parte melhora na exemplificação e argumentação. Seguem alguns exemplos das respostas abaixo:

Sim, cogumelo champinon e fermento de pão $(5.03 B)$.

Cogumelo, fermento de pão (5.04B).

Sim, os cogumelos podem ser alimentos, que nem o champignon (5.05A).

Tabela 13: Comparação entre os desempenhos pré e pós-teste Teste Wilcoxon

\begin{tabular}{|c|c|c|c|c|}
\hline Questão & Comparação & $\mathrm{N}^{\circ}$ Alunos & $\%$ & $\mathrm{P}$ \\
\hline Questão 1 & Melhor desempenho Pré & 0 & 0,0 & 0,0001 \\
\hline & Melhor desempenho Pós & 37 & 97,4 & \\
\hline & Desempenho Pré = Pós & 1 & 2,6 & \\
\hline & Total & 38 & 100,0 & \\
\hline & Questão 2 & 0 & 0,0 & 0,0001 \\
\hline & Melhor desempenho Pré & 30 & 100,0 & \\
\hline & Desempenho Pré = Pós & 0 & 0,0 & \\
\hline & Total & 30 & 100,0 & \\
\hline & Questão 3 & 0 & 0,0 & 0,0001 \\
\hline & Melhor desempenho Pré & 45 & 97,8 & \\
\hline & Desempenho Pré = Pós & 1 & 2,2 & \\
\hline & Total & 46 & 100,0 & \\
\hline & Melhor desempenho Pré & 0 & 0,0 & 0,0001 \\
\hline & Melhor desempenho Pós & 46 & 100,0 & \\
\hline & Desempenho Pré = Pós & 0 & 0,0 & \\
\hline & Total & 46 & 100,0 & \\
\hline & Melhor desempenho Pré & 0 & 0,0 & 0,0001 \\
\hline & Melhor desempenho Pós & 46 & 100,0 & \\
\hline & Desempenho Pré = Pós & 0 & 0,0 & \\
\hline & Total & 46 & 100,0 & \\
\hline
\end{tabular}




\begin{tabular}{|c|c|c|c|c|}
\hline Questão 6 & Melhor desempenho Pré & 7 & 13,5 & 0,0001 \\
\hline & Melhor desempenho Pós & 38 & 73,1 & \\
\hline & Desempenho Pré = Pós & 7 & 13,5 & \\
\hline & Total & 52 & 100,0 & \\
\hline \multirow[t]{4}{*}{ Questão 7} & Melhor desempenho Pré & 0 & 0,0 & 0,0001 \\
\hline & Melhor desempenho Pós & 50 & 96,2 & \\
\hline & Desempenho Pré = Pós & 2 & 3,8 & \\
\hline & Total & 52 & 100,0 & \\
\hline \multirow[t]{4}{*}{ Questão 8} & Melhor desempenho Pré & 0 & 0,0 & 0,0001 \\
\hline & Melhor desempenho Pós & 20 & 90,9 & \\
\hline & Desempenho Pré = Pós & 2 & 9,1 & \\
\hline & Total & 22 & 100,0 & \\
\hline \multirow[t]{4}{*}{ Questão 9} & Melhor desempenho Pré & 0 & 0,0 & 0,0001 \\
\hline & Melhor desempenho Pós & 21 & 95,5 & \\
\hline & Desempenho Pré = Pós & 1 & 4,5 & \\
\hline & Total & 22 & 100,0 & \\
\hline \multirow[t]{4}{*}{ Questão 10} & Melhor desempenho Pré & 0 & 0,0 & 0,0001 \\
\hline & Melhor desempenho Pós & 40 & 95,2 & \\
\hline & Desempenho Pré = Pós & 2 & 4,8 & \\
\hline & Total & 42 & 100,0 & \\
\hline \multirow[t]{4}{*}{ Questão 11} & Melhor desempenho Pré & 0 & 0,0 & 0,0001 \\
\hline & Melhor desempenho Pós & 9 & 21,4 & \\
\hline & Desempenho Pré = Pós & 33 & 78,6 & \\
\hline & Total & 42 & 100,0 & \\
\hline \multirow[t]{4}{*}{ Questão 12} & Melhor desempenho Pré & 0 & 0,0 & 0,0001 \\
\hline & Melhor desempenho Pós & 23 & 54,8 & \\
\hline & Desempenho Pré = Pós & 19 & 45,2 & \\
\hline & Total & 42 & 100,0 & \\
\hline
\end{tabular}

Estabelecendo-se um comparativo entre as respostas das questões anteriores (desempenho pré) e questões posteriores (desempenho pós) às atividades, pode-se evidenciar que na maioria das vezes as respostas melhoraram após a atividade.

É interessante ressaltar que em todas as atividades pode ser reconhecida a variedade e a riqueza de conhecimentos prévios apresentados nas respostas, independentemente se estes conceitos estavam corretos ou não.

E, também, houve a melhora na argumentação das respostas, pois, primeiramente, nas questões anteriores à atividade, muitas vezes as respostas se apresentaram de forma correta, porém os alunos não conseguiam explicar as respostas, não conheciam o "porquê", a explicação do fenômeno e este fato, na maioria das respostas, modificou-se posteriormente à atividade.
Ausubel (1978) considera um fator muito importante a valorização dos conhecimentos prévios do educando, que no caso do educando adulto se apresenta com grande riqueza em função da vivência que o mesmo possui.

Dessa forma, também deve ser considerada a utilização de estratégias que integrem a teoria e a prática, preferencialmente buscando trabalhar diretamente com o objeto de estudo que interesse ao aluno.

A utilização de atividades práticas torna a aula mais dinâmica, fator importante para o bom andamento da sala de aula, ainda mais quando se trata de educandos jovens e adultos, que frequentam o ensino noturno, que são trabalhadores e muitas vezes já vêm para a aula já cansados depois de um dia de trabalho.

À noite, há estudantes menos disponíveis, mas com uma vivência de trabalho. 
[...] no curso noturno, cabe ao professor estimular a aluno a fazer ponte entre o quadro conceitual apresentado e a experiência que ele próprio acumulou" (MARCOVITCH, 1998, p. 120).

Freire (1983) e Freire \& Betto (1985) evidenciam que quando a teoria é aliada à prática o aprendizado é favorecido, sendo que a teoria deve estar vinculada à percepção do mundo real, às situações cotidianas da vida do aluno. Assim, a teoria não se torna sem sentido e a palavra vazia, no entanto, o aluno consegue perceber a aplicabilidade do que está aprendendo e assim favorece o seu olhar mais interpretativo e crítico do mundo real.

Comenius também estabelece a importância do aprendizado da teoria aliada à prática através da utilização dos sentidos, quando afirma que o conhecimento deve ser iniciado com os sentidos:

O conhecimento deve necessariamente principiar pelos sentidos (uma vez que nada se encontra na inteligência sem que primeiro tenha passado pelos sentidos). Por que então o ensino há de principiar por uma exposição verbal das coisas, e não por uma observação real das mesmas coisas? Somente desta observação das coisas ter sido feita, virá a palavra, para explicar melhor (Comenius, 2001, p.270).

Nas atividades realizadas neste estudo, procurou-se sempre enfatizar a aplicabilidade ou a explicação prática dos fundamentos conceituais, sendo eles ligados ao cotidiano e a vivência do aluno.

Quando se realizou a atividade sobre os fungos, os mesmos foram relacionados com as doenças conhecidas pelos alunos, os fungos que são comestíveis ou alucinógenos, ao também muito conhecido mofo, ao fermento. Assim como na verificação da ciência que existe na cozinha, trabalhou-se tanto com a discussão de um texto que tratava de assuntos cotidianos quanto à atividade prática que foi a preparação de um mousse, exemplificando o tema trabalhado.

Nessas duas atividades, da caracterização dos fungos e da ciência na cozinha, percebeu-se uma riqueza muito grande nos conhecimentos prévios dos alunos, mesmo que as suas explicações não fossem totalmente corretas, as associações feitas por eles do assunto teórico com as situações cotidianas foram bem representativas, tanto que essas questões tiveram o maior número de desempenho igual nas questões pré e pós atividade.

Quando se tratou da existência do ar, da caracterização dos frutos e da mudança de estados físicos da água com a influência da temperatura, percebeu-se que existia nas respostas dos alunos algum conhecimento, porém, em sua maioria, desconheciam ou confundiam a explicação, o que foi modificado de forma representativa posteriormente às atividades realizadas.

\section{ANÁLISE DO ICD2 EJA}

Este questionário foi respondido por 30 educandos da EJA, que participaram das atividades realizadas. O ICD EJA2 foi elaborado no intuito de conhecer quais as atividades, na opinião dos alunos que participaram da pesquisa, despertam um maior interesse para que eles aprendam ciências.

A maioria dos alunos diz que o experimento é a estratégia mais interessante e também a mais motivadora para aprender ciências e, em segundo lugar, está a utilização de jogos pedagógicos no ensino de ciências. A grande maioria dos alunos também relatou ter se sentido mais independente (autonomia, motivação) ao realizar as atividades práticas propostas neste estudo do que com a aula somente teórica, não estabelecendo a relação entre a teoria e a prática.

Analisando este fato, para Delizoicov e Angotti (2000, p. 23), a atividade experimental "constitui-se num estímulo à curiosidade e à investigação experimental", atividade essa que deve ser utilizada como uma estratégia que propicie a discussão, a curiosidade, a criticidade, a interpretação dos dados obtidos, o desenvolvimento de conceitos e aplicabilidade da teoria na prática, sempre relacionado ao cotidiano do aluno.

Se não for dessa forma, a experimentação acaba por se tornar dogmática e autoritária, servindo de mera comprovação e execução de receitas prontas que aparecem em grande quantidade nos livros didáticos de ciências e que não contribuem em nada na formação do sujeito crítico que a transformação 
da escola atual tanto almeja.

Quanto à função do professor na sala de aula, a característica identificada como a mais importante pelos alunos foi do professor que é facilitador, daquele que facilita o processo de ensino e aprendizagem.

O fator mais importante para a permanência e o aproveitamento do aluno é a professora: o seu envolvimento, seu grau de preparação, sua disponibilidade para atender aos interesses dos alunos para mudar seu planejamento em virtude das necessidades específicas que surgem no decorrer do curso (Kleiman \& Signorini, 2001, p. 23).

Freire (2007, p.16 e 22) afirma que "formar é muito mais do que puramente treinar o educando no desempenho de destrezas [...] não é transferir conhecimento, mas criar possibilidades para a sua produção ou construção".

A postura do professor facilitador, que, para Freire, atua como formador, requer o uso de estratégias que sejam adequadas e ao mesmo tempo em que se aproximam da realidade e da vivência do educando estejam distantes do modelo de escolarização entediante e autoritário, que adota metodologias mais adequadas a um treinamento do que a uma formação crítica e motivadora, que permite e propicia ao aluno o aprender a aprender, a interpretação da e participação da sua realidade com autonomia

[...] a escola tem sido um lugar de tédio no lugar da construção do conhecimento; de autoritarismo no lugar de relações respeitosas entre professores e alunos e de memorização no lugar da criatividade e dos desafios. [...] A escola continua sendo um espaço de desconforto, desânimo, quando não um local para formar pessoas que irão reproduzir, mundo afora, atitudes rancorosas ou autoritárias (LEITE, 1999, 82).

E este é o papel do professor facilitador, facilitar o aprendizado, proporcionar situações que tornem a caminhada do educando rumo ao aprimoramento do conhecimento mais adequada, mais fácil, menos entediante, diminuindo os fatores que complicam o processo da educação, principalmente quando falamos de educandos adultos, cujas dificuldades de permanência na escola são muitas, o que acarreta em grande quantidade de desistências.

Na tabela 02, estão apresentadas as questões e suas respostas do ICD2 EJA, cujas respostas forma comentadas acima

Tabela 14 - Respostas x Freqüência ICD2 EJA.

\begin{tabular}{|c|c|c|c|}
\hline \multicolumn{4}{|c|}{ Questão 1 - Para você, qual a forma mais interessante de aprender Ciências? } \\
\hline A tividade & Jogos & $\begin{array}{l}\text { Experiment } \\
\text { os }\end{array}$ & $\begin{array}{l}\text { Saídas a } \\
\text { campo }\end{array}$ \\
\hline Freqüência & 10 & 12 & 8 \\
\hline$(\%)$ & $33,30 \%$ & $40 \%$ & $26,60 \%$ \\
\hline \multicolumn{4}{|c|}{$\begin{array}{l}\text { Questão } 2 \text { - Você se sentiu m ais motivado em aprender Ciências com a utilização } \\
\text { das atividades práticas (jogos, experimentos...)? }\end{array}$} \\
\hline Resposta & \multicolumn{2}{|c|}{\begin{tabular}{|l|l|} 
Sim & \\
\end{tabular}} & Não \\
\hline Freqüência & \multicolumn{2}{|c|}{29} & 1 \\
\hline$(\%)$ & \multicolumn{2}{|c|}{\begin{tabular}{|r|r|}
$96,60 \%$ & \\
\end{tabular}} & $3,30 \%$ \\
\hline \multicolumn{4}{|c|}{$\begin{array}{l}\text { Questão } 3 \text { - Coloque em grau de importância a atividade em que você se sentiu } \\
\text { mais motivado para aprender Ciências: }\end{array}$} \\
\hline Grau & $\begin{array}{r}\text { Mais } \\
\text { importante } \\
\end{array}$ & Mediano & $\begin{array}{l}\text { Menos } \\
\text { importante }\end{array}$ \\
\hline Atividade & Jogos & Jogos & Jogos \\
\hline Freqüência & 12 & 13 & 5 \\
\hline$(\%)$ & $40 \%$ & $43,30 \%$ & $16,60 \%$ \\
\hline A tividade & $\begin{array}{l}\text { Experiment } \\
\text { os }\end{array}$ & $\begin{array}{l}\text { Experiment } \\
\text { os }\end{array}$ & $\begin{array}{l}\text { Experimento } \\
\mathrm{s}\end{array}$ \\
\hline Freqüência & 13 & 12 & 5 \\
\hline$(\%)$ & $43,30 \%$ & $40 \%$ & $16,60 \%$ \\
\hline A tividade & $\begin{array}{l}\text { Saídas a } \\
\text { campo }\end{array}$ & $\begin{array}{l}\text { Saídas a } \\
\text { campo }\end{array}$ & $\begin{array}{l}\text { Saídas a } \\
\text { campo }\end{array}$ \\
\hline Freqüência & 5 & 5 & 25 \\
\hline$(\%)$ & $16,60 \%$ & $16,60 \%$ & $83,30 \%$ \\
\hline
\end{tabular}




\begin{tabular}{|c|c|c|c|}
\hline \multicolumn{4}{|c|}{ Questão 4 - Na sua opinião, qual a função do professor dentro da sala de aula? } \\
\hline Característica & Criativo & Informativo & Facilitador \\
\hline Freqüência & 5 & 8 & 11 \\
\hline$(\%)$ & $16,60 \%$ & $26,60 \%$ & $36,60 \%$ \\
\hline \multicolumn{3}{|c|}{ Questão 5 - Você se sentiu mais independente na realização das atividades } \\
propostas no decorrer dos nossos encontros? \\
\hline Resposta & Sim & Não \\
\hline Freqüência & 29 & $3,30 \%$ \\
\hline$(\%)$ & $96,60 \%$ & \\
\hline
\end{tabular}

\section{ANÁLISE DO ICD3 PROF. EJA}

O ICD 3 foi composto por seis perguntas abertas e foi respondido por cinco professores que trabalhavam regularmente com os educandos da EJA participantes das atividades propostas no decorrer do ano. A finalidade das questões é de reconhecer se houve na percepção dos professores, algum indício que demonstrasse a postura dos alunos diante da realização das atividades práticas no desenvolvimento dos conteúdos de Ciências.

A amostra é constituída de professores experientes e de áreas variadas - Disciplinas: Ciências, Educação Física, Matemática, Geografia e Português; Tempo de sala de aula: 10 anos, 11 anos, 17 anos, 18 anos e 23 anos. Seguem as questões:

1) Na sua opinião, a partir das atividades realizadas, os alunos sentiram-se mais motivados ao assistirem as aulas? Justifique.

Quando os professores foram questionados sobre a motivação dos alunos para assistirem às aulas, a partir de quando as atividades começaram a ser realizadas, percebese em suas falas que:

- Alguns alunos que tinham problemas de frequência e que faltavam as aulas, passaram a frequentar as aulas de segunda-feira, que era o dia em que se realizavam as aulas com as atividades prática;

- Assim como houve o interesse e pedido por parte dos alunos que os professores passassem a utilizar também atividades práticas nas outras aulas, aproximando assim a teoria da prática;
- Foi observado nos alunos aumento do interesse, da curiosidade, do raciocínio e que gostaram muito de realizar as atividades, sendo a aula de segunda-feira a mais esperada da semana.

Segue transcritas as respostas dos professores:

Sim, notei que muitos deles melhoram inclusive a frequência, pois estavam faltando muito e a partir dos encontros, passaram a frequentar as aulas de segunda-feira.

Sim, alguns até solicitaram que eu também utilizasse esse método nas minhas aulas e utilizasse material concreto, experimentos, coisas que aproximasse mais os conteúdos da aula com a vida real.

Sim, pois as aulas foram diferentes e além de despertar a curiosidade e o interesse deles, despertaram também o raciocínio.

Sim, sendo que os alunos gostaram muito da parte prática.

Sim, a aula de segunda era a mais esperada da semana. Os alunos adoram atividades diferentes, práticas e com certeza aprenderam muito com tudo isso.

A teoria de Freire evidencia o diálogo como um ponto chave para a educação crítica e partir da realidade concreta dos alunos, da sua vivência e utilizar suas experiências como ponto de partida para discussão não significa permanecer nelas, mas superá-las através do método crítico-dialógico, sendo esta uma estratégia motivadora, pois trabalha com $\mathrm{o}$ cotidiano do aluno, com algo que ele realmente conhece e considera importante. "Não é de 
surpreender, por isso, que se obtenham assim melhores resultados do que quando se introduzem conteúdos estranhos à sua realidade [...]" (FREIRE; GUIMARÃES, 1984, p. 103).

\section{2) Qual a validade desse tipo de atividade?}

Quanto à validade das atividades práticas voltadas para o cotidiano na EJA, percebe-se fortemente a ideia da teoria fazendo parte do cotidiano e da realidade do aluno. Bevilacqua e Coutinho (2007) consideram as atividades experimentais como ferramentas preciosas para o Ensino de Ciências, sendo fundamental que o aluno perceba os fenômenos científicos no seu cotidiano e que o 'fazer ciência' possa fazer parte do seu pensamento. Seguem as falas dos professores:

Motivou bastante e todos os conteúdos fazem parte da realidade do aluno.

Em primeiro lugar, a mudança de método utilizada pelo professor, aí então vamos conseguir que exista em qualquer prática educativa a interdisciplinaridade, fazendo com que o aluno construa seu conhecimento através de aulas mais práticas.

Eu acho que deve ser realizado com mais frequência e que deve haver a colaboração de outros professores para haver uma maior interação de todos os conteúdos.

Muito válida, pois a experiência sai do campo teórico e é realizada na prática, e os alunos acreditam mais na teoria quando vivenciam na prática.

Este tipo de atividade também propõe a dinamização do ensino, tornando as aulas mais interessantes, buscando a escola que queremos e se distanciando de muitas escolas que temos visto na atualidade.

3) Você percebeu alguma modificação na aprendizagem dos alunos após participarem dos encontros realizados? Justifique.

A partir das atividades realizadas, na percepção dos professores, os alunos passaram a se sentir mais interessados em aprender, mais participativos, passaram a questionar mais, melhoram na integração e no trabalho de grupo. Assim, como exemplificado em suas falas:

Sim, acredito que eles estejam menos resistentes à atividades diferenciadas.
Sim, devido a participação efetiva nos encontros os alunos ficaram bastante motivados.

Sim, as aulas ministradas pela professora, criou nos alunos um espírito de equipe.

Os alunos começaram a realizar mais questionamentos e mostraram interesse em aprender mais.

Para Freire, o processo educativo efetuado de forma dialógica, promovendo o diálogo e a formação do sujeito crítico, questionador, curioso, com autonomia, pode envolver mais trabalho, porém, estabelecendo-se um contraponto pode ser mais eficaz e conseguir resultados que pelo método de ensino passivo e reprodutor não seria possível.

Os métodos tradicionais, as abordagens de transferência de conhecimento são penosas precisamente porque não funcionam! Geram enorme resistência estudantil que temos que contornar na sala de aula (FREIRE, SHOR, 1986, p. 64).

Desse modo, ainda Araújo e Abib (2003) relatam que o uso de atividades experimentais como estratégia de ensino tem sido apontado por professores e alunos como uma das maneiras mais frutíferas de se minimizar as dificuldades, em aprender e ensinar Ciências de modo significativo e consistente.

\section{4)Você presenciou algum comentário dos alunos sobre as atividades realizadas? Comente.}

Nos comentários dos alunos, os professores evidenciaram que as experiências faziam parte da realidade e do cotidiano do aluno e que em muitas vezes os fenômenos eram conhecidos pelos alunos, porém não sabiam as explicações e os conceitos corretos ou totalmente corretos, visto que em muitas vezes tinham o conceito é parcialmente correto.

Também, em alguns comentários, pode-se identificar a curiosidade para o que seria trabalhado nas aulas seguintes e que se sentiram envolvidos, demonstrando satisfação e interesse em participar das aulas.

Seguem algumas afirmações dos professores que exemplificam:

Sim, algumas experiências realizadas nos encontros fazem parte da realidade dos alunos e 
são experiências que eles tinham, mas não sabiam as explicações.

O que eles mais comentavam era o que fariam na próxima aula.

Sim, porque os experimentos foram realizados de forma que os alunos se sentiram e estavam totalmente envolvidos.

Na aula depois das atividades eles ficavam comentando o que tinham feito, pareciam crianças quando fazem uma novidade.

Sim, vi muitos falando do encontro que tratou sobre a química na cozinha.

A postura do professor em sala, bem como a adequação das estratégias que desenvolve em sala de aula, é um fator de muita importância na aprendizagem, $\mathrm{O}$ professor deve estar disposto a atender aos interesses dos alunos, estabelecendo a dialética, assim como evidenciam Kleiman e Signorini (2001, p. 23):

O fator mais importante para a permanência e o aproveitamento do aluno é a professora: o seu envolvimento, seu grau de preparação, sua disponibilidade para atender os interesses dos alunos para mudar seu planejamento em virtude das necessidades específicas que surgem no decorrer do curso.

Através da fala dos professores da EJA, nível de ensino em que o trabalho foi desenvolvido, percebeu-se a aceitação dos alunos da EJA quanto às atividades desenvolvidas. Percebe-se que eles gostaram das atividades, se sentiram motivados e satisfeitos.

Também, enquanto professora, a pesquisadora pôde perceber o interesse dos alunos através da postura e interesse que demonstravam em relação às aulas. Eles se apresentavam animados, perguntavam questionavam e demonstravam a sua apreciação ao desenvolvimento das atividades.

\section{CONSIDERAÇÕES FINAIS}

A pesquisa realizada desenvolveu um conjunto de atividades práticas do cotidiano relacionadas aos conteúdos de Ciências na EJA Ensino Fundamental. Buscou-se com isto investigar as consequências no desenvolvimento do processo de compreensão e da construção conceitual, na percepção de educandos e docentes.
Analisou-se o desempenho dos educandos da EJA quanto ao uso das atividades práticas no processo de ensino e aprendizagem em Ciências, identificando as mudanças conceituais relacionadas à compreensão dos conteúdos trabalhados e confirmou-se que ocorreu um crescimento significativo nas respostas e argumentações dos alunos, após a realização das atividades propostas.

Assim, considera-se que os conteúdos de Ciências desenvolvidos através de atividades práticas, de forma discutida e relacionada ao cotidiano e à vivência do educando jovem e adulto, tende a ser uma ferramenta facilitadora no processo de ensino e aprendizagem, aliado a isto se estabelece a grande importância da valorização dos conhecimentos prévios do educando jovem e adulto para a sua formação efetiva.

\section{REFERÊNCIAS}

ARAÚJO, M. S.T. \& ABIB, M.L.V.S. Atividades experimentais no ensino de física: diferentes enfoques, diferentes finalidades. Rev. Bras. Ens. Fis. Vol.25, n.2. São Paulo/SP, junho/2003. Dis poníve 1 e m http://www.scielo.br/scielo.php?pid=S0102$47442003000200007 \&$ script $=$ sci_arttext\&tlng =es. Acesso em: 03/08.

AUSUBEL, D. P. Psicologia educativa: Um punto de vista cognoscitivo. México: Trilhas, 1978.

BEVILACQUA, G. D. \& COUTINHO-SILVA, R. O Ensino de Ciências na $5^{a}$ série através da experimentação. Ciências \& Cognição; Ano 04, Vol 10, pp. 84-92. 2007. Disponível em www.cienciasecognicao.org. Acesso em: 04/08

BRASIL. MINISTÉRIO DA EDUCAÇÃO. Programa Nacional da Educação profissional com a Educação Básica na modalidade de Educação de Jovens e Adultos - PROEJA / Ensino Fundamental - Documento Base/2006. Brasília, DF, 2007.

COMENIUS, J. A. A Didática Magna. Tradução de Joaquim Ferreira Gomes (2001). Disponível em: www.ebooksbrasil.org 
DELIZOICOV, D. \& ANGOTTI, J. A. Metodologia do Ensino de Ciências. São Paulo, SP: Ed. Cortez, 1994.

FREIRE. Educação e mudança. 6. ed. Rio de Janeiro: Paz e Terra, 1983.

FREIRE, P.; Betto, F. Essa escola chamada vida: depoimentos ao repórter Ricardo Kotscho. São Paulo: Ática, 1985.

FREIRE, Paulo; GUIMARÃES, Sérgio. Sobre educação: (diálogos): volume 1. Rio de Janeiro: Paze Terra, 1982.

FREIRE, Paulo; SHOR, Ira. Medo e ousadia: o cotidiano do professor. Tradução de Adriana Lopez. Rio de Janeiro: Paz e Terra, 1986.

HADDAD, S. Educação de pessoas jovens e adultas e a nova $L D B$. In BRZEZINSKY, I. (org.) LDB interpretada: diversos olhares que se entrecruzam. São Paulo/SP: Cortez, 1997.

KLEIMAM, A.; SIGNORINI, I. (org.) O ensino e a formação do professor: Alfabetização de jovens e adultos. Porto Alegre/RS: Artmed, 2001. LEITE, D. Pedagogia Universitária: Conhecimento, ética e política no ensino superior. Porto Alegre/RS:UFRGS, 1999.

MARCOVITCH, J. A Universidade (im)possível. São Paulo/SP: Futura, 1998.

PINTO, A. V. Sete lições sobre Educação de Adultos. 14 ${ }^{\mathrm{a}}$ ed. São Paulo/SP: Cortez, 2005.

SOARES, L. (org). Aprendendo com a diferença Estudos e pesquisas em Educação de Jovens e Adultos. Belo Horizonte/MG: Autêntica, 2005.

ZAGO, N. Processos de escolarização nos meios populares. In SOARES, L. Aprendendo com a diferença. Belo Horizonte/ MG: Autêntica, 2005. 